\title{
Análise da realização dos exames laboratoriais no diagnóstico da Dengue no Piauí
}

\author{
Analysis of the performance of laboratory tests in the diagnosis of Dengue in Piauí \\ Análisis del desempeño de las pruebas de laboratorio en el diagnóstico de Dengue en Piauí
}

Recebido: 18/09/2021 | Revisado: 26/09/2021 | Aceito: 27/09/2021 | Publicado: 29/09/2021

Raí Emanuel da Silva
ORCID: https://orcid.org/0000-0002-4266-0475
Universidade Federal do Piaú, Brasil
E-mail: raiemanuel@ hotmail.com
Alda Cássia Alves da Silva
Universidade Federal do Piauí, Brasil
E-mail: aldacassia_ads@ hotmail.com
Dakson Douglas Araújo
ORCID: https:/orcidorgon-0003-3194-1471
ORCID: https://orcid.org/0000-0003-0102-7240
Universidade Federal do Delta do Parnaíba, Brasil
E-mail: dacksondouglas@gmail.com
Nathanael dos Santos Alves
ORCID: https://orcid.org/0000-0001-6945-6282
Universidade Federal do Delta do Parnaíba, Brasil
E-mail: santosnathanael55@gmail.com
Artur Alexandre de Oliveira
ORCID: https://orcid.org/0000-0003-3373-1929
Universidade Federal do Delta do Parnaíba, Brasil
E-mail: arthuralexandre125@hotmail.com
Ingredy Lopes dos Santos
ORCID: https://orcid.org/0000-0003-1205-4340
Universidade Federal do Piaú, Brasil
E-mail: ingredy_lopes@ hotmail.com
Marina Sandy da Silva Mendes
ORCID: https://orcid.org/0000-0002-8985-7857
Faculdade Uninassau Parnaíba, Brasil
marinassandy@ hotmail.com
Jéssyca Christina Fortes Ramos

\section{Resumo}

O agente etiológico da dengue é um arbovírus, com quatro diferentes sorotipos (DENV 1, 2, 3 e 4), transmitido pelo mosquito Aedes aegypti. Todos os sorotipos podem ocasionar diversas manifestações clínicas, que variam de sintomas leves até sintomas mais graves, conduzindo até mesmo ao óbito. O presente estudo teve como objetivo analisar os casos de dengue no Piauí, notificados entre os anos de 2014 e 2020, e avaliar a frequência de realização de exames laboratoriais essenciais ao diagnóstico desta arbovirose no estado. Nesse contexto, o estudo trata-se de uma pesquisa epidemiológica descritiva, de caráter retrospectivo e transversal, com abordagem quantitativa, com coleta de dados na plataforma digital de Doenças e Agravos de Notificação do Sistema Nacional de Informação de Agravos e Notificação (SINAN/DATASUS). Verificou-se que 38.093 casos de dengue foram registrados no estado. Foi observado que do total de casos, a maior parte $(57,49 \%)$ aconteceu em mulheres, e que a população mais acometida foi a de adultos jovens (20-39 anos). Ao se analisar parâmetros relacionados ao diagnóstico da dengue, verificou-se o registro de dados como "não realizados" ou "ignorados/em branco" sobrepondo-se aos exames realizados (positivo/negativo/inconclusivo), como na detecção de anticorpos IgM, exames sorológicos de ELISA e isolamento viral. Os sorotipos DENV-1 e DENV-2 foram os mais detectados no Piauí. Portanto, observa-se que o diagnóstico clínico-epidemiológico tem se sobreposto frente à realização de exames diagnósticos. Contudo, vale salientar que a realização de testes laboratoriais permite um acompanhamento preciso e específico da evolução e disseminação da infecção no estado.

Palavras-chave: Arbovirose; Dengue; Diagnóstico laboratorial; Levantamento epidemiológico.

\section{Abstract}

The etiologic agent of dengue is an arbovirus, with four different serotypes (DENV 1, 2, 3 and 4), transmitted by the Aedes aegypti mosquito. All serotypes can cause several clinical manifestations, ranging from mild symptoms to more 
severe symptoms, even leading to death. This study aimed to analyze the cases of dengue in Piauí, reported between 2014 and 2020, and to assess the frequency of laboratory tests essential for the diagnosis of this arbovirus in the state. In this context, the study is a descriptive, retrospective and cross-sectional epidemiological research, with a quantitative approach, with data collection on the digital platform of Diseases and Conditions of Notification of the National System of Information on Diseases and Notification (SINAN/DATASUS ). It was found that 38,093 cases of dengue were registered in the state. It was observed that out of the total number of cases, the majority $(57.49 \%)$ occurred in women, and that the most affected population was young adults (20-39 years). When analyzing parameters related to the diagnosis of dengue, it was verified the recording of data as "not performed" or "ignored/blank" overlapping the exams performed (positive/negative/inconclusive), as in the detection of IgM antibodies, ELISA serological tests and viral isolation. The DENV-1 and DENV-2 serotypes were the most detected in Piauí. Therefore, it is observed that the clinical-epidemiological diagnosis has been superimposed on the performance of diagnostic tests. However, it is noteworthy that the performance of laboratory tests allows a precise and specific monitoring of the evolution and spread of the infection in the state.

Keywords: Arboviruses; Dengue; Laboratory diagnosis; Epidemiological survey.

\section{Resumen}

El agente etiológico del dengue es un arbovirus, con cuatro serotipos diferentes (DENV 1, 2, 3 y 4), transmitido por el mosquito Aedes aegypti. Todos los serotipos pueden causar varias manifestaciones clínicas, que van desde síntomas leves hasta síntomas más graves, e incluso pueden provocar la muerte. Este estudio tuvo como objetivo analizar los casos de dengue en Piauí, notificados entre 2014 y 2020, y evaluar la frecuencia de las pruebas de laboratorio esenciales para el diagnóstico de este arbovirus en el estado. En este contexto, el estudio es una investigación epidemiológica descriptiva, retrospectiva y transversal, con enfoque cuantitativo, con recolección de datos en la plataforma digital de Enfermedades y Condiciones de Notificación del Sistema Nacional de Información sobre Enfermedades y Notificación (SINAN/DATASUS ). Se constató que en el estado se registraron 38.093 casos de dengue. Se observó que del total de casos, la mayoría (57,49\%) ocurrieron en mujeres, y que la población más afectada fueron los adultos jóvenes (20-39 años). Al analizar los parámetros relacionados con el diagnóstico de dengue, se verificó el registro de datos como "no realizado" o "ignorado/en blanco" superponiendo los exámenes realizados (positivo / negativo / no concluyente), como en la detección de anticuerpos IgM, ELISA serológico pruebas y aislamiento viral. Los serotipos DENV-1 y DENV-2 fueron los más detectados en Piauí. Por tanto, se observa que el diagnóstico clínico-epidemiológico se ha superpuesto a la realización de pruebas diagnósticas. Sin embargo, es de destacar que la realización de pruebas de laboratorio permite un seguimiento preciso y específico de la evolución y propagación de la infección en el estado.

Palabras clave: Arbovirus; Dengue; Diagnóstico de laboratorio; Encuesta epidemiológica.

\section{Introdução}

A dengue é uma infecção viral provocada por quatro diferentes sorotipos de dengue vírus, os quais são referidos como

DENVs 1-4. Estes integram a família Flaviviridae, possuindo um genoma com uma única fita de RNA de senso-positivo. O principal vetor da infecção é a fêmea do mosquito Aedes aegypti, comumente encontrado em regiões tropicais e subtropicais do mundo. Entretanto surtos recentes de dengue em regiões temperadas demonstram um novo vetor, o mosquito Aedes albopictus, o que amplia o cenário de regiões afetadas por essa enfermidade (Muller, Depelsenaire \& Young, 2017; Kraemer et al., 2015).

A infecção com qualquer um dos quatro sorotipos da dengue pode resultar em diversos tipos de manifestações, desde uma doença febril indiferenciada leve, a dengue clássica que se caracteriza por temperatura elevada (até $40{ }^{\circ} \mathrm{C}$ ), com dor de cabeça intensa, dores articulares e musculares, dor retro orbital, mal-estar, náuseas e vômitos, com erupção cutânea que aparece após três ou quatro dias após o início da febre. Os pacientes podem ser assintomáticos ou apresentar quadros de febre hemorrágica grave (Bhatt et al., 2013; Lin, Lee \& Leo, 2017). Após uma infecção primária com um dos sorotipos, o paciente é imunologicamente protegido da doença causada por esse sorotipo, entretanto, não adquire imunidade cruzada contínua contra os sorotipos restantes (Khetarpal \& Khanna, 2016).

A dengue é um grave problema de saúde pública. Alguns estudos têm demonstrado que a incidência de dengue na região da América Latina-Caribe aumentou no período 1995-2010 (a incidência combinada foi de 72,1/100.000 pessoas/ano) (Cafferata et al., 2013). Outros estudos recentes mostram que 390 milhões de pessoas têm infecções pelo vírus da dengue, com 96 milhões de casos por ano em todo o mundo, mais de três vezes a estimativa da Organização Mundial de Saúde de 2012 (Bhatt et al., 2013; Lin, Lee \& Leo, 2017). 
O diagnóstico da infecção geralmente é realizado pela detecção do genoma viral, por meio da técnica de RT-PCR, pesquisa de anticorpos IgM produzidos em resposta à infecção, através do método imunoenzimático de ELISA, ou ainda através da identificação do antígeno NS1, proteína viral liberada por células infectadas pela DENV, e que aparecem na corrente sanguínea no início da infecção. Além destas, inclui-se ainda nos métodos diagnósticos, o ensaio anatomopatológico, com subsequente pesquisa de antígenos virais por imunohistoquímica (Brasil, 2009; Licks, 2013).

Esses são métodos específicos utilizados na maioria dos laboratórios para detectar o DENVs, e que envolvem a caracterização viral pela detecção de antígenos específicos com captura de antígeno NS1, através do método de ELISA e a detecção indireta de anticorpos IgM e IgG. A detecção do genoma do vírus da dengue ocorre através da amplificação do genoma viral, por meio reação em cadeia da polimerase (do inglês Polymerase Chain Reaction), com transcrição reversa (RTPCR) ou de forma quantitativa (qPCR), sendo estas as ferramentas adequadas para a identificação e determinação de diferentes sorotipos da dengue (WHO, 2012).

No Brasil, o Ministério da Saúde recomenda a aplicação do protocolo em que pacientes com suspeita de dengue devem ser relatados e terem uma amostra de sangue coletada para diagnóstico. Nesse processo, a detecção dos antígenos virais NS1, isolamento do vírus, o RT-PCR e os ensaios de imuno-histoquímica devem ser solicitados até o quinto dia do início dos sintomas. Adicionalmente, a sorologia pelo método de ELISA, deve ser solicitada no sexto dia após o aparecimento dos sintomas. A infecção por dengue não pode ser excluída em amostras negativas para o antígeno NS1 e deve ser confirmada para detecção de IgM/IgG (Brasil, 2016). Ainda no país, adota-se que todas as amostras suspeitas de dengue devem ser sorotipadas. O PCR protocolo de Lanciotti, Calisher, Gubler, Chang \& Vorndam (1992) é usado para confirmação, inclusive é considerado o protocolo padrão ouro para a identificação de sorotipos por técnicas de PCR e qPCR (Salles et al., 2018). Entretanto, o diagnóstico clínico da dengue pode ser desafiador, dependendo principalmente de qual estágio da infecção o paciente se encontra. Dependendo ainda da região geográfica, pode haver uma série de patógenos causadores de enfermidades ou estados de doenças que podem assemelhar-se ao espectro decorrente da infecção por dengue (WHO, 2009).

Nesse sentido, na prática, o diagnóstico da dengue ocorre sobretudo, a partir de exames médicos, observando-se as características clínicas apresentadas pelos pacientes. Contudo, ressalta-se que além da similaridade com outras arboviroses, o que pode comprometer o diagnóstico clínico, deve-se considerar a importância do diagnóstico preciso e confiável, por meio de testes laboratoriais (Maniero et al., 2016). No Piauí, o número de casos de dengue apresentou uma elevação ao longo do tempo, observando a ocorrência de 28.219 casos, entre 2015 e 2019 (Souza et al., 2020).

Entretanto, embora o supracitado estudo tenha apresentado dados epidemiológicos para um período próximo ao avaliado neste levantamento (2014-2020), aqui apresenta-se uma análise com foco na execução dos testes laboratoriais, uma vez que o Ministério da Saúde preconiza em suas diretrizes a realização de tais ensaios para a confirmação do diagnóstico da dengue (Brasil, 2016). Um acompanhamento dessas ações permite uma análise aprofundada do sistema, cabendo assim sugestões de medidas que visem colaborar com os órgãos de saúde. Desta forma, partindo desta premissa e considerando que não há na literatura estudos que descrevem uma análise crítica acerca da realização dos exames laboratoriais da dengue no Piauí, o presente estudo teve como objetivo avaliar os casos de dengue e a frequência de realização dos exames laboratoriais no diagnóstico da arbovirose no Piaú, entre os anos de 2014 e 2020.

\section{Metodologia}

O estudo trata-se de uma pesquisa epidemiológica descritiva, de caráter retrospectivo e transversal, com abordagem quantitativa (Patrocínio et al., 2020). A investigação foi conduzida a partir das informações epidemiológicas disponibilizadas na aba "Informações de Saúde (TABNET)/Epidemiológicas e Morbidade", no tópico Doenças e Agravos de Notificação do Sistema Nacional de Informação de Agravos e Notificação (SINAN/DATASUS), do Ministério da Saúde, registradas entre os 
anos de 2014 e 2020, no estado do Piauí. Neste estudo, considerou-se duas classes de dados para avaliação, tais como as características sociais e as informações diagnósticas referente a infeção pelo vírus da dengue.

Desta maneira incluiu-se a análise do número de casos de dengue, o sexo dos pacientes e a faixa etária acometida, o que correspondeu a primeira classe de dados analisados e objetivamente, a realização do diagnóstico da dengue foi avaliada pelo levantamento dos testes realizados, o que incluiu o exame sorológico IgM, a realização do exame sorológico pelo método de ELISA, o isolamento viral e a identificação do sorotipo do vírus da dengue. Os dados obtidos no presente estudo foram tabulados e analisados, para fins de comparação, identificando-se as diferenças entre os índices apresentados pelo SINAN, para o período avaliado. Os resultados são apresentados em formato de tabelas e gráficos, organizados pelo Software Microsoft Excel 2013.

Por se tratar de uma pesquisa com dados de livre acesso disponibilizados no SINAN, o estudo não necessitou de aprovação do Comitê de Ética em Pesquisa (CEP, conforme estabelecido pelo conteúdo normativo da resolução $\mathrm{n}^{\circ} 466 / 12$ do Conselho Nacional de Saúde.

\section{Resultados e Discussão}

A dengue trata-se de uma doença negligenciada endêmica no Brasil e que apresenta grande importância clínica e epidemiológica, no contexto de saúde pública (Guerra-Gomes et al., 2017). Conforme objetivo traçado inicialmente, neste trabalho apresenta-se um levantamento dos casos de dengue a frequência de realização dos exames laboratoriais, registrados no estado do Piauí, entre os anos de 2014 a 2020, no Sistema de Informação de Agravos de Notificação, do Ministério da Saúde.

Segundo a base de dados do DATASUS, um total de 38.093 casos de dengue foram registrados no estado. Entre os anos de 2015 e 2018 houve uma redução gradativa no número de casos de dengue no Piauí, registrando-se o menor índice para este último ano $(2018 / \mathrm{n}=1.935 ; 5,08 \%)$. Entretanto, observou-se a ocorrência de um aumento considerável no ano de 2019 $(\mathrm{n}=8.027 ; 21,07 \%)$, se comparado ao ano anterior. Nisso, destaca-se a grande elevação do número de casos em 2019 , resultando no ano de maior índice de notificação, conforme apresentado no Gráfico 1.

Gráfico 1 - Número de casos de dengue registrados no Piauí no período de 2014 a 2020.

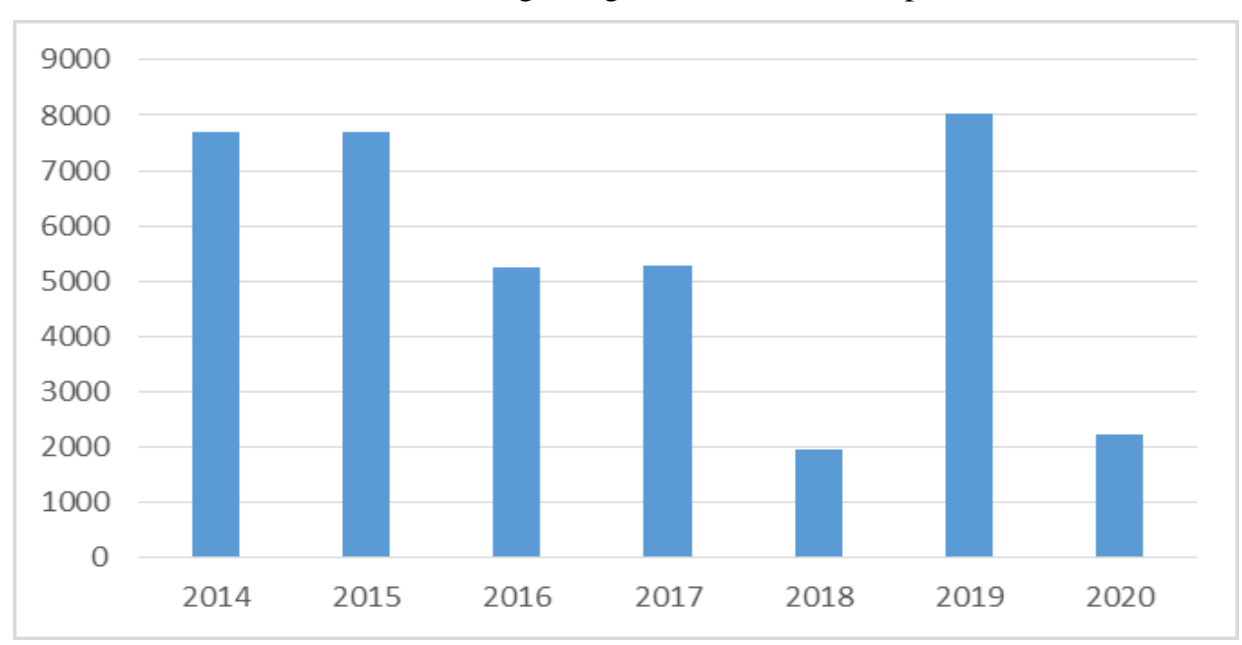

Fonte: Ministério da Saúde, Sistema de Informação de Agravos de Notificação - SINAN.

Os dados deste trabalho corroboram com dados descritos anteriormente e com os de Souza et al. (2020) que descreveu um total de 28.219 casos entre os anos de 2015 a 2019, no Piauí. Da mesma maneira, outros estudos também já relataram uma 
ocorrência elevada da arbovirose no estado no passado, como o estudo de Castro et al. (2003) que descrevem uma alta ocorrência de casos de dengue vírus no ano de 2000, com um aumento contínuo ao longo dos anos seguintes analisados.

Além disso, quando se compara os casos notificados no Piauí com o estado do Ceará, observa-se um maior número de casos notificados de dengue vírus naquele estado, principalmente no ano de 2015 (Lima et al., 2019). Esse fato pode ser decorrente do maior número de habitantes no estado do Ceará, bem como do maior controle de notificações no estado.

Considerando o sexo dos pacientes, do total de casos notificados de dengue entre os anos de 2014 e 2020 no Piauí, foram registrados 21.900 (57,49\%) casos para o sexo feminino, 16.126 (42,33\%) para o sexo masculino e em 67 casos $(0,18 \%)$ tal dado não foi informado (ignorado/em branco) (Gráfico 2).

Gráfico 2 - Número de casos de dengue de acordo com o sexo dos pacientes, no período de 2014 a 2020 no Piauí.

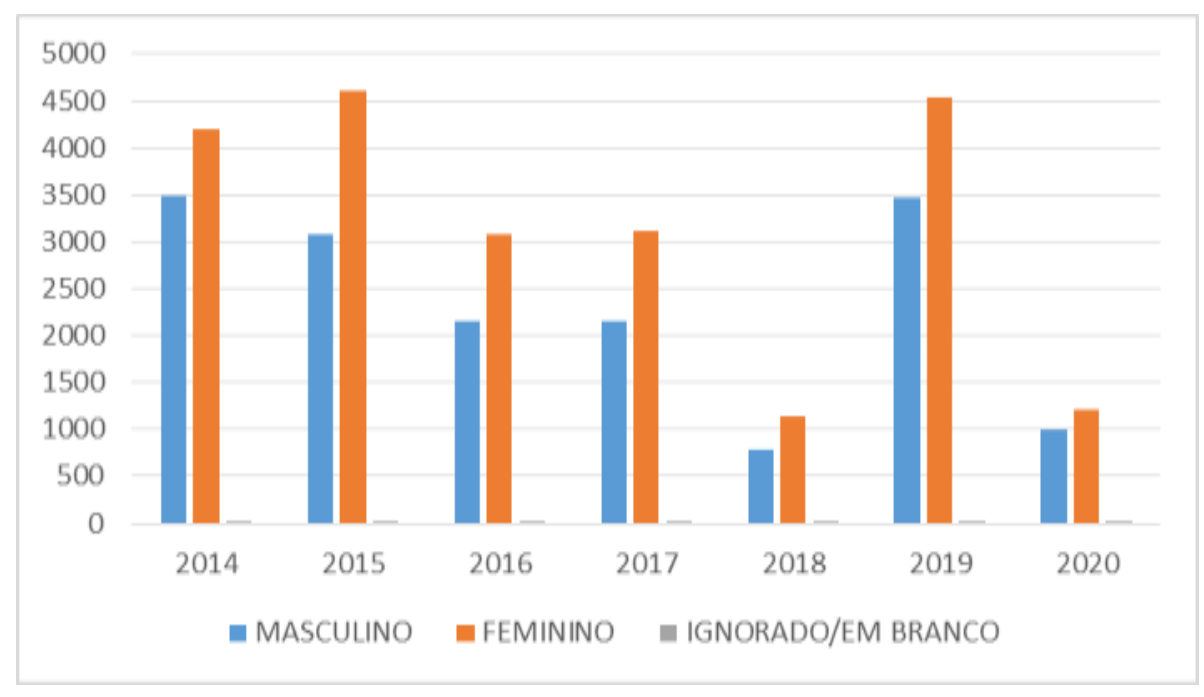

Fonte: Ministério da Saúde, Sistema de Informação de Agravos de Notificação - SINAN.

Esse perfil do sexo feminino ser o mais afetado corrobora com os dados de Souza et al. (2020) referente ao estado do Piauí. Entretanto, como já descrito em outros estudos, esse maior acometimento nas mulheres, não é relacionado a um maior risco quanto ao sexo em si, mas sim à permanência da mesma no ambiente domiciliar, local onde a transmissão da arbovirose ocorre em maior proporção (Barbosa et al., 2012; Oliveira, Araújo \& Cavalcante, 2018). Além disso, acrescenta-se ainda o fato da maior frequência diagnóstica, como reflexo da maior procura pelos serviços de saúde por parte das mulheres, quando comparadas aos homens (Levorato, Mello, Silva \& Nunes, 2014).

Ao analisar a faixa etária dos indivíduos acometidos pela dengue, observou-se que a população mais acometida foi a de adultos jovens (20-39 anos), que teve o maior número de casos registrados no período avaliado no presente estudo ( $\mathrm{n}=$ 16.068; 42,18\%). Nisso, o ano de 2015 se destaca com o maior índice de indivíduos dessa faixa etária acometidos pela arbovirose (n=3.478; 9,13\%). Entre 2014 e 2020, a segunda faixa etária com o maior número de casos correspondeu aos indivíduos com idade entre 40-59 anos, que totalizaram 8.002 casos (21,01\%). Por outro lado, os indivíduos com mais de 80 anos, entretanto, representaram a classe com menor número de casos $(\mathrm{n}=330 ; 0,87 \%)$ na pesquisa (Tabela 1$)$. 
Tabela 1 - Número de casos de dengue, de acordo com a faixa etária, no período de 2014 a 2020 no Piauí.

\begin{tabular}{ccccccccc}
\hline FAIXA ETÁRIA & $\mathbf{2 0 1 4}$ & $\mathbf{2 0 1 5}$ & $\mathbf{2 0 1 6}$ & $\mathbf{2 0 1 7}$ & $\mathbf{2 0 1 8}$ & $\mathbf{2 0 1 9}$ & $\mathbf{2 0 2 0}$ & TOTAL \\
\hline $\begin{array}{c}\text { Ignorado/em } \\
\text { branco }\end{array}$ & N/A & 2 & N/A & 2 & N/A & 5 & 1 & 10 \\
$<\mathbf{1}$ & 123 & 115 & 120 & 60 & 38 & 184 & 47 & 687 \\
$\mathbf{1}-\mathbf{4}$ & 214 & 250 & 148 & 99 & 47 & 214 & 76 & 1048 \\
$\mathbf{5 - 9}$ & 457 & 370 & 238 & 224 & 81 & 614 & 133 & 2117 \\
$\mathbf{1 0 - 1 4}$ & 702 & 460 & 345 & 329 & 96 & 825 & 173 & 2930 \\
$\mathbf{1 5}-\mathbf{1 9}$ & 930 & 751 & 549 & 553 & 210 & 917 & 208 & 4118 \\
$\mathbf{2 0}-\mathbf{3 9}$ & 3220 & 3478 & 2238 & 2225 & 890 & 3100 & 917 & 16068 \\
$\mathbf{4 0 - 5 9}$ & 1520 & 1738 & 1096 & 1182 & 402 & 1551 & 513 & 8002 \\
$\mathbf{6 0}-\mathbf{6 4}$ & 185 & 204 & 152 & 184 & 66 & 213 & 50 & 1054 \\
$\mathbf{6 5}-\mathbf{6 9}$ & 137 & 149 & 137 & 161 & 38 & 169 & 33 & 824 \\
$\mathbf{7 0}-\mathbf{7 9}$ & 162 & 142 & 157 & 169 & 56 & 175 & 46 & 907 \\
$\mathbf{8 0}+$ & 41 & 43 & 64 & 88 & 13 & 61 & 20 & 330 \\
TOTAL & 7691 & 7702 & 5244 & 5276 & 1937 & 8028 & 2217 & 38095 \\
\hline
\end{tabular}

Fonte: Ministério da Saúde, Sistema de Informação de Agravos de Notificação - SINAN.

Os resultados referentes à distribuição por grupo etário, assemelha-se aos estudos realizados em Teresina (Monteiro, Coelho, Cunha, Cavalcante \& Carvalho, 2009) e Rio Grande do Norte (Barbosa et al., 2012), visto que os indivíduos com maior proporção de casos foram de adultos jovens. De modo semelhante, Almeida et al. (2021) verificaram que os indivíduos adultos com idade entre 20-59 anos, foram os que mais adoeceram por dengue entre 2001 e 2018, no estado do Mato Grosso, com uma taxa de incidência de 604,9 para cada 100 mil habitantes.

Considerando que a confirmação do diagnóstico da dengue por meio de exames laboratoriais trata-se de um procedimento estabelecido nos protocolos do Ministério da Saúde (Brasil, 2016), a execução de tais testes é de extrema importância, contribuindo assim para o acompanhamento soroepidemiológico da infecção. Vale ressaltar que o diagnóstico laboratorial é importante para diferenciar as doenças existentes, obtendo-se assim um dado seguro e não apenas baseado em sinais e sintomas, visto que muitas infecções apresentam sintomas semelhantes à dengue, como por exemplo, a Zika e a Chikungunya (Monteiro et al., 2016).

Analisando os resultados do exame sorológico IgM para dengue, foi observado que uma grande quantidade de testes não foi realizada entre os pacientes com provável infecção pelo vírus da dengue, totalizando 20.127 (52,84\%). O ano de 2014 se destacou pela maior quantidade de testes positivos $(n=1.752 ; 27,08 \%)$, seguido por 2019 ( $n=1.530 ; 23,65 \%)$. Considerando a contribuição da pesquisa de anticorpos $\operatorname{IgM}$ para o diagnóstico das infecções, a sobreposição do número de ensaios não realizados, em todos os anos analisados, frente a quantidade de ensaios positivos, destaca-se como uma preocupação no acompanhamento soro-epidemiológico da dengue no Piauí (Gráfico 3). 
Gráfico 3 - Número de exame sorológico IgM para dengue, no período de 2014 a 2020 no Piauí.

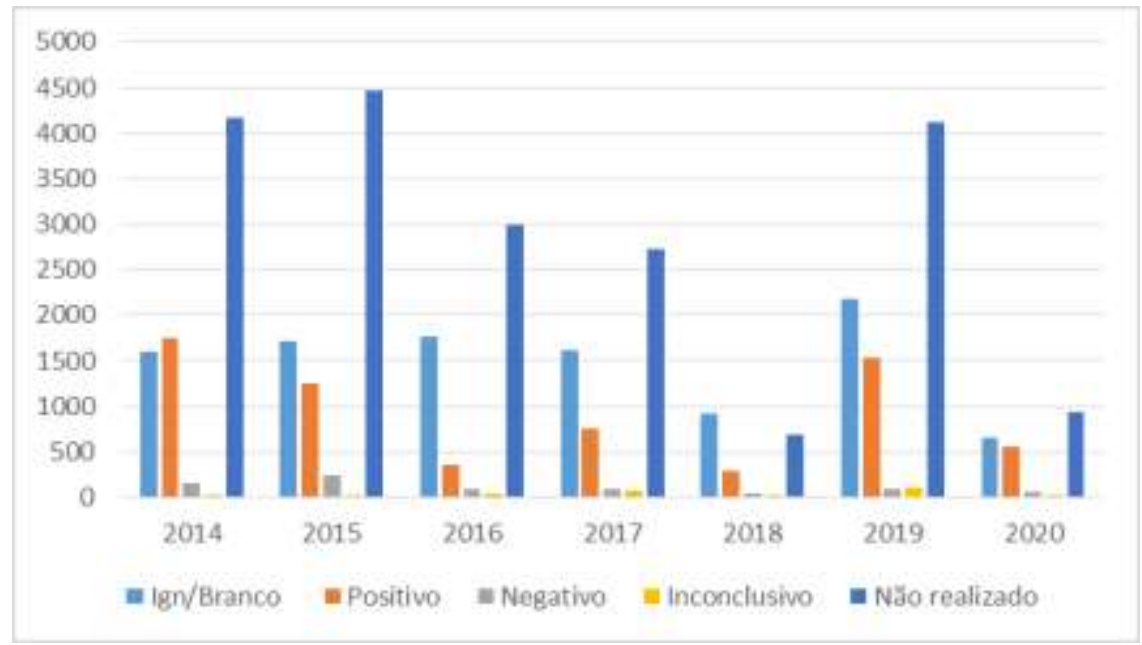

Fonte: Ministério da Saúde, Sistema de Informação de Agravos de Notificação - SINAN.

Segundo o Ministério da Saúde, a detecção de anticorpos IgM no sangue é realizada na fase inicial da doença (fase aguda). Geralmente, estas imunoglobulinas apresentam-se elevadas a partir do $4^{\circ}$ dia, após o início dos sintomas. Desta forma, o exame sorológico pode ser conduzido desde os primeiros dias de infecção até quatro semanas após o aparecimento dos primeiros sintomas. Estas moléculas diminuem posteriormente, não sendo detectáveis após alguns meses da manifestação dos sintomas (Brasil, 2009; Saito, Machado, Medina, \& Paschoalato, 2017).

A pesquisa por IgM no diagnóstico da dengue, quando realizada no período adequado, representa uma alternativa de fácil execução, sendo um importante método de rotina, capaz de confirmar o quadro infeccioso e apresentar resultados satisfatórios, essencial para o diagnóstico dos casos suspeitos (Gerace et al., 2015; Biassoti \& Ortiz, 2017). Dada tal informação, e analisando o Gráfico 3, chama-se atenção para a não realização do referido ensaio em 20.127 (52,84\%) casos prováveis de dengue no Piaú́, nos últimos sete anos. Isso demonstra a necessidade de se reavaliar a forma como o diagnóstico da dengue tem sido conduzido no estado, de maneira que se priorize a execução de ensaios laboratoriais que possam confirmar a infecção.

A realização de ensaios imunoenzimáticos como pelo método de ELISA contribui para o diagnóstico do DENV. Desta forma, avaliou-se a realização de exames sorológicos por tal método, e seguindo o mesmo padrão observado no Gráfico 3, os números de ensaios Ignorados/Em branco ou que não foram realizados, se sobrepõem frente ao número de exames realizados (positivo, negativo ou inconclusivo). Um total de 24.116 (63,30\%) exames não foram executados e em 12.939 (33,96\%) dos casos suspeitos de dengue, essa informação é apresentada como ignorada/em branco. A positividade da infecção pelo DENV foi confirmada em apenas $502(1,32 \%)$ dos casos (Gráfico 4). 
Gráfico 4 - Número de exame sorológico ELISA para dengue, no período de 2014 a 2020 no Piauí.

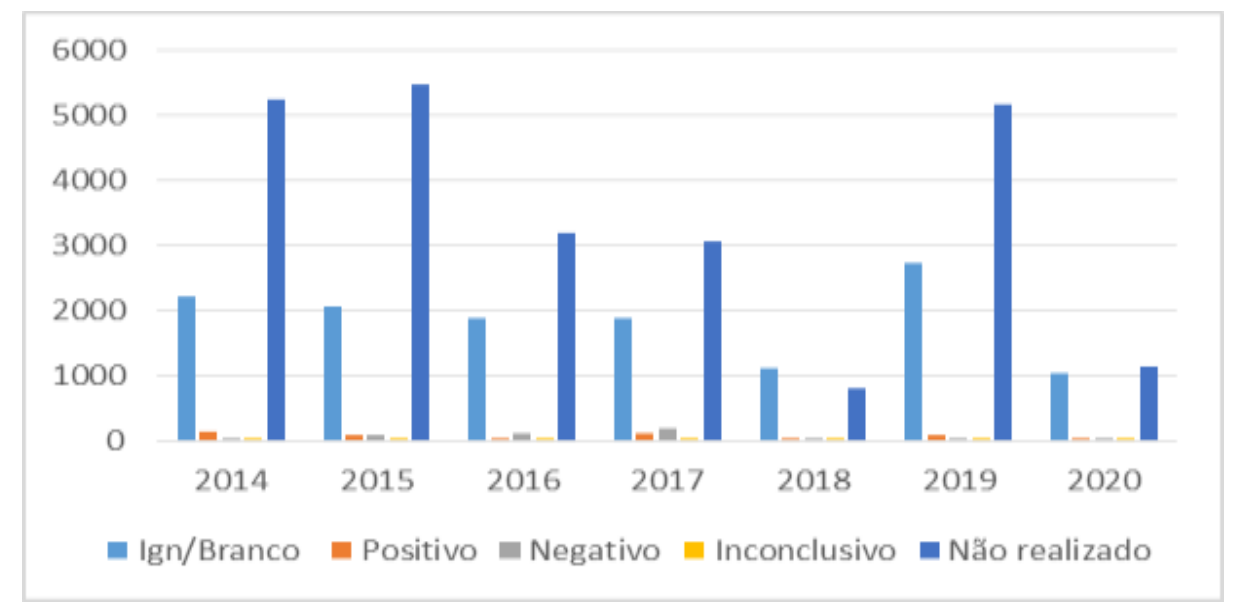

Fonte: Ministério da Saúde, Sistema de Informação de Agravos de Notificação - SINAN.

A realização do exame de ELISA relaciona-se com a detecção de antígenos virais específicos do DENV, como NS1. A identificação desse antígeno por tal método, configura-se como um ensaio seguro, sensível e específico, que pode ser utilizado inclusive em casos mais graves (Brasil, 2009). O exame de isolamento viral é considerado o padrão-ouro no diagnóstico da dengue. Para a sua execução, pode-se utilizar de amostras de sangue, líquido céfalo-raquidiano (LCR) e fragmentos de vísceras. Para amostras de sangue, sua coleta deve ser realizada até o $5^{\circ}$ dia do início dos sintomas, preferencialmente (Brasil, 2009). Nesse contexto, considerando o mesmo perfil de diagnóstico para os exames sorológicos de IgM e ELISA, há destaque para a não realização de testes de isolamento viral nos anos avaliados. Assim, foi observado que do total de número de casos de dengue registrados, em 25.495 (66,92\%) o teste de isolamento viral não foi realizado, em 12.484 $(32,77 \%)$ a realização de tal teste não foi informada, em 65 casos $(0,17 \%)$ o resultado foi negativo e em $33(0,08 \%)$ foi possível isolar o vírus da dengue. O teste foi considerado inconclusivo em 16 (0,04\%) casos (Gráfico 5).

Gráfico 5 - Número de exames de isolamento viral para dengue, no período de 2014 a 2020 no Piauí.

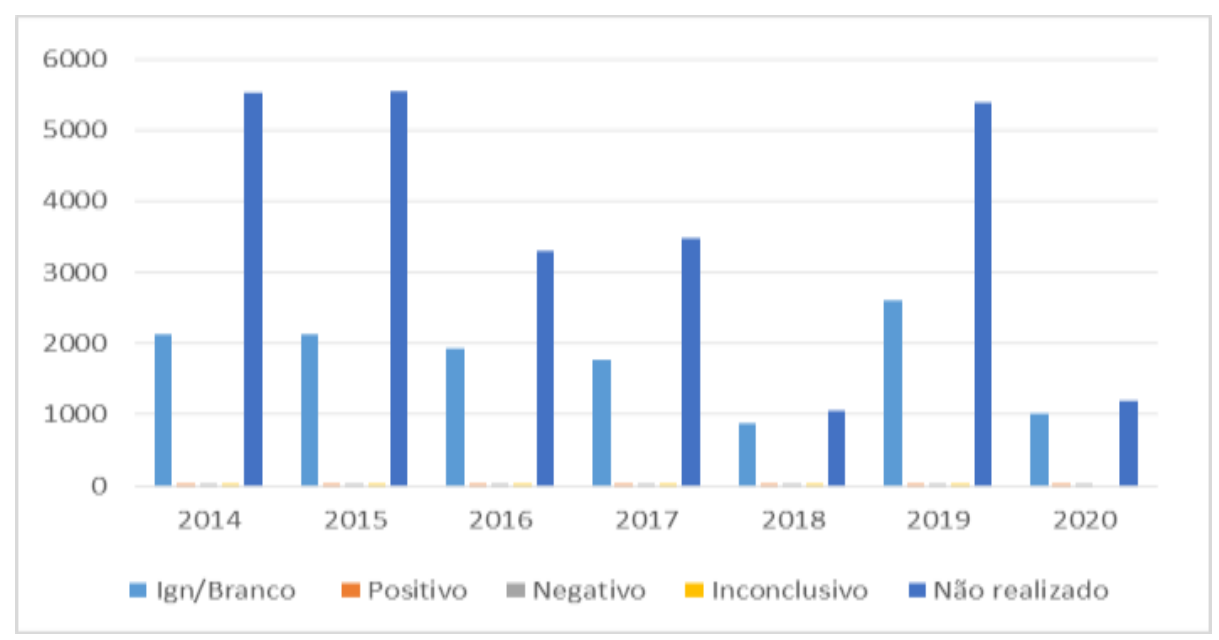

Fonte: Ministério da Saúde, Sistema de Informação de Agravos de Notificação - SINAN.

No estudo de Rabelo, Amâncio, Oiko, Ferraz, e Carneiro (2020) o parâmetro de isolamento viral também foi avaliado. Os autores identificaram que o teste foi realizado em $67,2 \%$ dos casos e que é importante considerar que a quantidade de testes não realizados possa ter ocorrido pelo fato que esse ensaio só é indicado até o quinto dia após o início de sintomas. Lettry, 
Tobias e Teixeira (2021) observaram que de 7.903 casos prováveis de dengue registrados no município de Senador Canedo, estado de Goiás, 7.681 (97,19\%) não realizaram o exame de isolamento viral. Nisso, considerando que muitas vezes os pacientes tardam a procurar o serviço de saúde ou não procuram, isso diminui o número de pacientes com amostra apta para tal exame. Ainda nesse contexto, é importante considerar que tanto o presente estudo como o estudo mencionado, as análises foram realizadas com base em dados secundários coletados no banco de dados do DATASUS, com possível perda de dados e falta de informações.

Segundo o DATASUS, a pesquisa pelo sorotipo da dengue (DEN-1, DEN-2, DEN-3 e DEN-4), totalizou 295 testes entre 2014 e 2020. Observa-se que o ano de 2019 destaca-se com o maior número de realizações, com 139 testes positivos para o sorotipo DEN-1 e 78 para o sorotipo DEN-2. Estes foram os sorotipos mais pesquisados em todos os anos, totalizando 201 e 91 investigações para DEN-1 e DEN-2, respectivamente, no período analisado. Além disso, é importante destacar o fato de que em 37.798 casos, essa informação foi ignorada, segundo o sistema, conforme apresentado no Gráfico 6.

Gráfico 6 - Identificação dos sorotipos da dengue no Piauí entre 2014 e 2020.

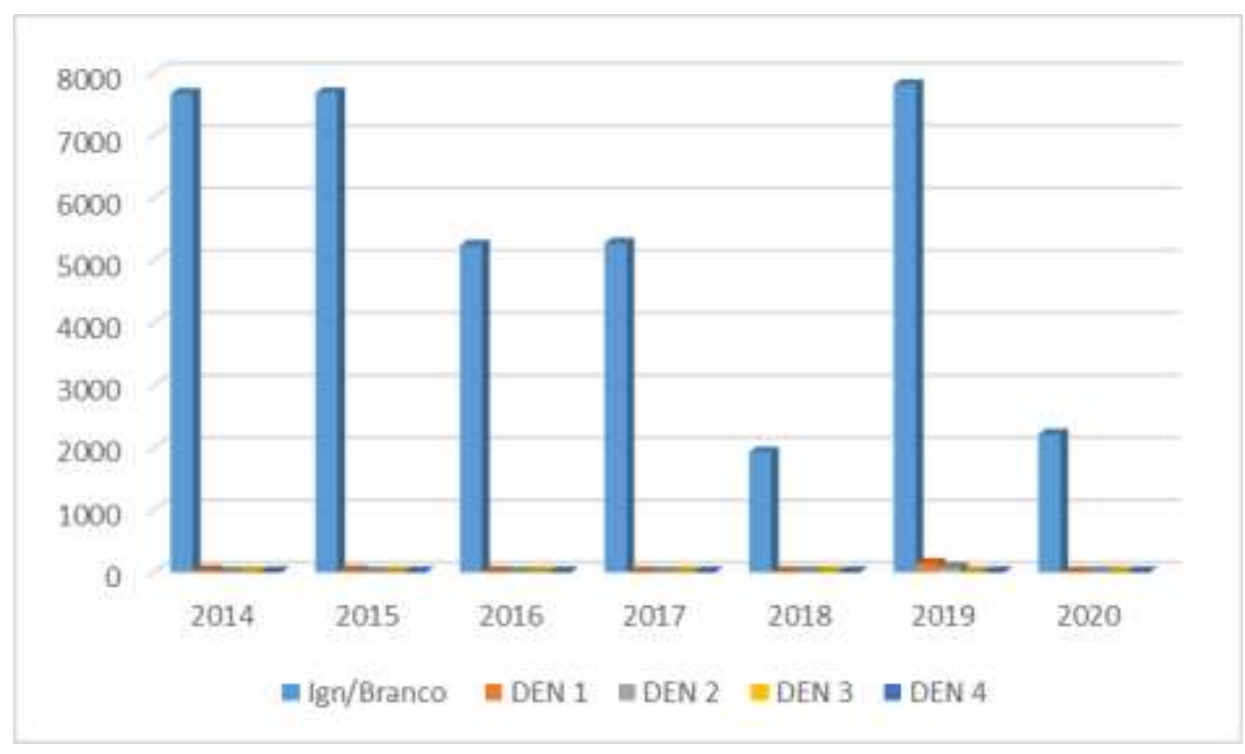

Fonte: Ministério da Saúde, Sistema de Informação de Agravos de Notificação - SINAN.

Em um período anterior ao analisado no presente estudo, o Ministério da Saúde relatou que no ano 2006 o Piauí notificou 4.759 casos de dengue, e que entre os anos de 2006 e 2007, o DENV-2 e DENV-3 foram os sorotipos mais prevalentes no estado (Castro et al., 2003; Figueiredo et al., 2014). Por outro lado, ao se avaliar o contexto nacional, verifica-se que de maneira semelhante ao perfil para o Piauí, entre 2014 e 2020, os dados históricos de outros estudos demonstram que entre os anos de 2009 e 2016, o sorotipo da doença com mais incidência no Brasil, foi DENV-1. Em 2015, a prevalência do sorotipo DENV-1 atingiu cerca de 94,1\%. O segundo sorotipo mais prevalente naquele ano foi o DENV-4 com 4,8\%. O perfil em 2016 se reproduziu, observando-se uma prevalência 91,24\% para o DENV-1 e 1,38\% para o sorotipo DENV-4 (Lopes, Silva, Pastor, \& Silva, 2018). Entretanto, no ano seguinte (2017) registrou-se um aumento na identificação do sorotipo DENV2 com 54,3\% foi o mais incidente (Brasil, 2018).

O perfil de sobreposição observado para o parâmetro de Ign/Branco para dados analisados no Piauí, assemelha-se ao observado por Lettry, Tobias e Teixeira (2021), que avaliaram o perfil de distribuição dos casos de dengue registrados no período de 2014 a 2018, em município do estado de Goiás. Os autores identificaram que dos 7.903 casos notificados, apenas em cinco casos foi realizada a identificação do sorotipo, com destaque para os 7.895 casos em que o sorotipo do vírus da 
dengue foi ignorado ou registrado como em branco. Esses achados chamam atenção e geram preocupação para a forma como os órgãos de saúde avaliam o padrão de circulação viral em suas regiões, pois encara-se que com a identificação dos sorotipos é possível traçar estratégias que visem acompanhar a disseminação do agente etiológico em uma dada área.

Tanto a técnica de isolamento viral, como a de identificação dos sorotipos do DENV são técnicas importantes para o diagnóstico preciso e correto da infecção. O protocolo da OMS instrui que o isolamento viral envolve o cultivo celular, geralmente, o da linhagem de mosquito (clone C6/36, Aedes albopictus), com posterior uso da imunofluorescência indireta, por meio de anticorpos monoclonais, contra os quatro sorotipos do vírus (Igarashi, 1978; Gubler, Kuno, Sather, Velez, \& Oliver, 1984). A realização do isolamento viral é uma das alternativas propostas pelo Ministério da Saúde para a confirmação laboratorial de uma infecção pelo vírus da dengue (Brasil, 2009). Ainda segundo o documento, este ensaio é considerado o padrão ouro, sendo desta forma mais específico para se isolar e identificar o sorotipo causador do quadro infeccioso.

Considerando o número total de casos de dengue registrado entre os anos de 2014 e 2020, chama-se atenção para o fato de que as variáveis relacionadas ao diagnóstico, e analisadas no presente estudo, tais como exame sorológico IgM, exame sorológico ELISA, isolamento viral e identificação dos sorotipos da dengue, apresentam índices de não realização extremamente elevados, se comparados ao número total de casos registrados. Isso deve ser encarado como um fator preocupante na confirmação dos casos de dengue no Piauí, sugerindo que as notificações registradas consideram sobretudo os aspectos clínicos/epidemiológicos da infecção, minimizando desta maneira a relevância da realização de ensaios laboratoriais. Isso corrobora quando se observa a ocorrência do registro de informações de casos com diagnostico laboratorial positivo, mas que são encerrados como critério clinico (Brasil, 2009).

No contexto da medicina laboratorial, é importante destacar que a realização de exames que auxiliem o clínico na identificação do agente causador da infecção permite um acompanhamento seguro do caso, bem como estabelece o melhor tratamento para o paciente, reduzindo desta forma as chances do desenvolvimento de casos mais graves da dengue (Biassoti \& Ortiz, 2017). Adicionalmente, além de destacar a não realização dos testes laboratoriais avaliados, destaca-se também a ocorrência de registros de dados como ignorados ou em brancos, e nesse sentido, reitera-se as observações realizadas pelo Ministério da Saúde em suas diretrizes. É importante salientar a importância da qualidade dos dados registrados no Sistema, onde informações oriundas de fichas de notificação ou investigação, com campos em branco, inconsistentes ou duplicidade de registros, indicam para a necessidade de uma reavaliação do sistema da qualidade dos dados coletados e registrados no DATASUS (Brasil, 2009).

\section{Conclusão}

A realização de investigações epidemiológicas permite acompanhar o cenário e a evolução de uma determinada doença em uma região. Desta forma, estas investigações podem ser conduzidas tanto em campo, como através do levantamento de dados/informações disponibilizadas pelo Sistema de Agravos de Notificações do Ministério da Saúde, tal como a apresentada no presente estudo. Dentro da proposta exposta inicialmente, foi possível observar que dentro do número de casos de dengue notificados no Piauí, entre os anos de 2014 e 2020, há destaque para os dados em que informações importantes para o diagnóstico laboratorial da dengue, são registradas como não realizadas ou ignoradas/em branco.

Diante destes achados, demonstra-se que no Piauí o diagnóstico clínico-epidemiológico da infecção tem se sobreposto frente à realização de exames diagnósticos, tais como sorologia, isolamento viral, bem como a identificação dos sorotipos do DENV. Entretanto, é importante considerar que o correto diagnóstico, realizado por profissional capacitado e por meio de técnicas apropriadas, permite um acompanhamento preciso e específico da evolução e disseminação da infecção no estado, bem como auxilia os profissionais médicos na tomada de decisão e condução do tratamento do paciente, minimizando a ocorrência de casos graves. Ainda nesse contexto, é importante salientar que a execução dos exames possibilita aos órgãos de 
saúde um acompanhamento soro-epidemiológico da dengue, de maneira que se possa traçar ações que visem reduzir a transmissão do vírus da dengue que, somada às estratégias de combate à transmissão do seu vetor, são capazes de minimizar a ocorrência de novos casos.

Desta forma, é importante considerar a realização constante de novas investigações como a realizada no presente estudo, de modo a se avaliar a execução dos exames laboratoriais nos casos notificados e registrados pelo Ministério da Saúde, visando um acompanhamento atualizado e que permita a promoção e estabelecimento de estratégias junto aos órgãos de saúde responsáveis, em prol da saúde da população.

\section{Referências}

Barbosa, I. R., Araújo, L. D. F., Carlota, F. C., Araújo, R. S., \& Maciel, I. J. (2012). Epidemiologia do dengue no Estado do Rio Grande do Norte, Brasil, 2000 a 2009. Epidemiologia e Serviços de Saúde, 21(1), 149-157.

Bhatt S, Gething P. W, Brady O. J, et al. The global distribution and burden of dengue. Nature 2013; 496:504-7.

Biassoti, A. V., \& Ortiz, M. A. L. (2017). Diagnóstico laboratorial da dengue. Revista Uningá Review, 29(1).

Brasil. (2009). Ministério da Saúde (MS). Secretaria de Vigilância em Saúde. Departamento de Vigilância Epidemiológica. Diretrizes nacionais para a prevenção e controle de epidemias de dengue. MS.

Brasil. (2016). Ministério da Saúde. Secretaria de Vigilância em Saúde. Departamento de Vigilância Epidemiológica: Dengue: diagnóstico e manejo clínico: adulto e criança. [recurso eletrônico] / Ministério da Saúde, Secretaria de Vigilância em Saúde, Departamento de Vigilância das Doenças Transmissíveis. 5. ed. Ministério da Saúde.

Brasil. (2018). Ministério da Saúde. Secretaria de Vigilância em Saúde. Monitoramento dos casos de dengue, febre de chikungunya e febre pelo vírus Zika até a Semana Epidemiológica 5 de 2018. Boletim Epidemiológico. 49:1-14.

Castro, J. A. F. D., Andrade, H. M. D., Monte, S. J. H. D., Silva, A. S. D., Gomes, K. C. B. L., Cipriano, F. D. O., \& Miagostovich, M. P. (2003). Atividade do vírus da dengue no Piaú, Brasil. Memórias do Instituto Oswaldo Cruz, 98 (8), 1021-1023.

Cafferata, M. L., Bardach, A., Rey-Ares, L., Alcaraz, A., Cormick, G., Gibbons, L., \& Ruvinsky, S. (2013). Dengue epidemiology and burden of disease in Latin America and the Caribbean: a systematic review of the literature and meta-analysis. Value in health regional issues, 2(3), $347-356$.

De Almeida, T. G, Rieder, A., Junior, E. S. O, Muniz, C. C, Ramos, A. O, \& Pereira, P. A (2021). Aspectos epidemiológicos da dengue no Estado de Mato Grosso, Brasil: série temporal 2001-2018. Research, Society and Development, 10 (6), e32610615716-e32610615716.

Figueiredo, L. B., Sakamoto, T., Leomil Coelho, L. F, de Oliveira Rocha, E. S, Gomes Cota, M. M, Ferreira, G. P, \& Kroon, E. G (2014). Dengue virus 2 American-Asian genotype identified during the 2006/2007 outbreak in Piauí, Brazil reveals a Caribbean route of introduction and dissemination of dengue virus in Brazil. PLoS One, 9(8), e104516.

Gerace, S. M., Silva, E. A. D. D. S., Carolina, A., De Souza, E. B. P., Manini, E. C., \& Minto, M. V. A. Avaliação dos métodos de ELISA para antíg eno NS1 e anticorpos IgM, no diagnóstico da dengue, durante a epidemia ocorrida em 2013, no município de Ribeirão Preto, São Paulo, Brasil.

Gubler, D. J., Kuno, G., Sather, G. E., Velez, M., \& Oliver, A. N. D. A. (1984). Mosquito cell cultures and specific monoclonal antibodies in surveillance for dengue viruses. The American journal of tropical medicine and hygiene, 33(1), 158-165.

Igarashi, A. (1978). Isolation of a Singh's Aedes albopictus cell clone sensitive to Dengue and Chikungunya viruses. Journal of General Virology, 40(3), 531544.

Khetarpal, N., \& Khanna, I. (2016). Dengue: causas, complicações e estratégias de vacinação. Journal of Immunology Research, 2016.

Kraemer, M. U., Sinka, M. E., Duda, K. A., Mylne, A. Q., Shearer, F. M., Barker, C. M., \& Hay, S. I. (2015). The global distribution of the arbovirus vectors Aedes aegypti and Ae. albopictus. elife, 4, e08347.

Lanciotti, R. S., Calisher, C. H., Gubler, D. J., Chang, G. J., \& Vorndam, A. V. (1992). Rapid detection and typing of dengue viruses from clinical samples by using reverse transcriptase-polymerase chain reaction. Journal of clinical microbiology, 30(3), 545-551.

Lettry, T. C. R. N., Tobias, G. C., \& Teixeira, C. C. (2021). Perfil Epidemiológico De Dengue Em Senador Canedo-Goiás, Brasil. Revista Uningá,58, eUJ3722-eUJ3722.

Levorato, C. D., Mello, L. M. D., Silva, A. S. D., \& Nunes, A. A. (2014). Fatores associados à procura por serviços de saúde numa perspectiva relacional de gênero. Ciência \& saúde coletiva, 19, 1263-1274.

Licks J. G. D. S. (2013). Caracterização da investigação laboratorial de casos suspeitos de dengue no Estado de Goiás. (Dissertação de Mestrado). Universidade Federal de Goiás, Goiânia, GO, Brasil.

Lima, G. A., Lima, F. E. T., do Nascimento, I. C. F., Rodrigues, R. R., Rocha, D. M. A., da Costa, C. O., \& Sandoval, L. J. S. (2019). Casos de dengue em Fortaleza: um estudo epidemiológico documental. Brazilian Applied Science Review, 3(5), 2252-2262.

Lin, R. J., Lee, T. H., \& Leo, Y. S. (2017). Dengue in the elderly: a review. Expert review of anti-infective therapy, 15(8), 729-735. 
Research, Society and Development, v. 10, n. 12, e531101220776, 2021

(CC BY 4.0) | ISSN 2525-3409 | DOI: http://dx.doi.org/10.33448/rsd-v10i12.20776

Lopes, T. R. R., Silva, C. S., Pastor, A. F., \& Silva, J. V. J. (2018). Dengue no Brasil em 2017: o que aconteceu? Revista do Instituto de Medicina Tropical de São Paulo, 60 .

Monteiro, E. S. C., Coelho, M. E., Cunha, I. S. D., Cavalcante, M. D. A. S., \& Carvalho, F. A. D. A. (2009). Aspectos epidemiológicos e vetoriais da dengue na cidade de Teresina, Piauí-Brasil, 2002 a 2006. Epidemiologia e Serviços de Saúde, 18(4), 365-374.

Muller, D. A.; Depelsenaire; A. C. I.; Young, P. R. Clinical and Laboratory Diagnosis of Dengue Virus Infection. The Journal of Infectious Diseases 2017; 215(S2):S89-95.

Nascimento, L. B. D., Siqueira, C. M., Coelho, G. E., \& Siqueira, J. B. (2017). Dengue em gestantes: caracterização dos casos no Brasil, 20072015. Epidemiologia e Serviços de Saúde, 26, 433-442.

Oliveira, R. D. M. A. B., Araújo, F. M. D. C., \& Cavalcanti, L. P. D. G. (2018). Aspectos entomológicos e epidemiológicos das epidemias de dengue em Fortaleza, Ceará, 2001-2012. Epidemiologia e serviços de saúde, 27, e201704414.

Patrocínio, D. C. B., Ribeiro, A. B. B. G., Fernandes, V. D. G., de Alencar, L. B. B., de Azevedo, J. D. F., de Sousa, S. C. A., \& de Oliveira Filho, A. A. (2020). Análise epidemiológica dos casos de intoxicações exógenas por plantas medicinais no estado da Paraíba. Research, Society and Development , 9 (7), e855975011-e855975011.

Rabelo, A. C. L., Amâncio, F. F., Oiko, C. S. F., Ferraz, M. L., \& Carneiro, M. (2020). Caracterização dos casos confirmados de dengue por meio da técnica de linkage de bancos de dados, para avaliar a circulação viral em Belo Horizonte, 2009-2014. Epidemiologia e Serviços de Saúde, 29 , e2019354.

Ribeiro, G. S, Kikuti, M., Tauro, L. B, Nascimento, L. C. J., Cardoso, C.W., Campos, G. S., \& Sardi, SI (2018). A imunidade após a infecção pelo zika vírus tem proteção cruzada contra a dengue ?. The Lancet Global health , 6 (2), e140-e141.

Saito, C. K., Machado, S. C. P., Medina, W. S. G., \& Paschoalato, A. B. P. (2017). Sorologia e avaliação clínica: correlação no diagnóstico da Dengue. Cuidarte, Enferm, Catanduva, 1(11), 72-77.

Salles, T. S., da Encarnação Sá-Guimarães, T., de Alvarenga, E. S. L., Guimarães-Ribeiro, V., de Meneses, M. D. F., de Castro-Salles, P. F., \& Moreira, M. F. (2018). History, epidemiology and diagnostics of dengue in the American and Brazilian contexts: a review. Parasites \& Vectors, 11(1).

World Health Organization. (2009). Dengue: guidelines for diagnosis, treatment, prevention and control. New edition. WHO.

World Health Organization. (2012). Special Programme for Research and Training in Tropical Diseases. Handbook for clinical management of dengue. World Health Organization. 